\title{
A NOTE ON VECTOR-VALUED MAXIMAL MULTILINEAR OPERATORS AND THEIR COMMUTATORS
}

\author{
ZENGYAN Si AND QINGYING XUE
}

Abstract. Let $T^{*}$ be the maximal multilinear Calderón-Zygmund operator with kernels of Dini's type and $T_{q}^{*}(\vec{f})$ be the vector-valued version of $T^{*}$. In this paper, we consider the weighted norm inequalities for $T_{q}^{*}(\vec{f})$. As applications, the weighted strong type and weighted end-point weak type estimates for the commutators of $T_{q}^{*}(\vec{f})$ were established respectively.

Mathematics subject classification (2010): 42B20, 42B25.

Keywords and phrases: Maximal multilinear operators, multilinear Calderón-Zygmund operators, commutators, vector-valued inequalities.

\section{REFERENCES}

[1] T. A. Bui, X. T. DuONG, Weighted norm inequalities for multilinear operators and applications to multilinear Fourier multipliers, Bull. Sci. Math. 137 (2013), 63-75.

[2] X. CHEN, Weighted estimates for maximal operator of multilinear singular intergral, Bull. Polish Acad. Sci. Math. 58 (2010), 129-135.

[3] R. R. CoIfman AND Y. MeYeR, On commutators of singular integrals and bilinear singular integrals, Trans. Amer. Math. Soc. 212 (1975), 315-331.

[4] R. R. Coifman And Y. Meyer, Commutateurs d'intégrales singulières et opérateurs multilinéaires, Ann. Inst. Fourier, Grenoble 28 (1978), 177-202.

[5] R. R. Coifman And Y. Meyer, Au-delà des opérateurs pseudo-différentiels, Asterisque 57, 1978.

[6] D. CruZ-Uribe, J. M. MARTEll AND C. PÉREZ, Extrapolation from $A_{\infty}$ weights and applications, J. Func. Anal. 213 (2004), 412-439.

[7] J. Duonndikoetxea, Fourier Analysis, Graduate Studies in Math. 29, Amer. Math. Soc., Providence, Rhode Island, 2001.

[8] X. T. Duong, L. Grafakos, L. Yan, Multilinear operators with non-smooth kernels and commutators of singular integrals, Trans. Amer. Math. Soc. 362 (2010), 2089-2113.

[9] C. Fefferman and E. Stein, Some maximal inequalities, Amer. J. Math. 93 (1971), 107-115.

[10] L. Grafakos And R. Torres, Multilinear Calderón-Zygmund theory, Adv. Math. 165 (2002), $124-164$

[11] L. GRAFAKOS AND J. M. MARTELL, Extrapolation of weighted norm inequalities for multivariable operators, J. Geom Anal. 14 (2004), 19-46.

[12] L. GRAFAKOS, L. LIU AND D. YANG, Multiple weighted norm inequalities for maximal multilinear singular integrals with non-smooth kernels, Proc. Roy. Soc. of Edinburgh Sect. A 141 (2011), 755 775.

[13] L. Grafakos, R. H. Torres, Maximal operator and weighted norm inequalities for multilinear singular integrals, Indiana Univ. Math. J. 51 (2002), 1261-1276.

[14] G. HU, C.-C. LiN, Weighted norm inequalities for multilinear singular integral operators and applications, Anal. Appl. 12 (2014), 269-291.

[15] A. K. Lerner, S. Ombrosi, C. Pérez, R. H. Torres and R. Trujillo-González, New maximal functions and multiple weights for the multilinear Calderón-Zygmund theory, Adv. Math. 220 (2009), 1222-1264. 
[16] G. LU, P. ZhANG, Multilinear Calderón-Zygmund operators with kernels of Dini's type and applications, Nonlinear Anal. 107 (2014), 92-117.

[17] B. Moukenhoupt, Weighted norm inequalities for the Hardy maximal function, Trans. Am. Math. Soc. 165 (1972), 207-226.

[18] D. Maldonado, V. NAIBo, Weighted norm inequalities for paraproducts and bilinear pseudodifferential operators with mild regularity, J. Fourier Anal. Appl. 15 (2009), 218-261.

[19] C. PÉREZ AND R. H. TORRES, Sharp maximal function estimates for multilinear singular integrals, Harmonic Analysis at Mount Holyoke, Contemporary Mathematics 320 (2003), 323-331.

[20] C. PÉREZ AND R. TRujILlo-GonZÁLEZ, Sharp weighted estimates for multilinear commutators, J. London Math. Soc. 65 (2002), 672-692.

[21] C. Pérez, G. Pradolini, R. H. Torres and R. Trujillo-GonZÁlez, End-point estimates for iterated commutators of multilinear singular integrals, to appear in Journal of London Math. Soc..

[22] C. PÉREZ AND R. H. TORRES, Minimal regularity conditions for the end-point estimate of bilinear Calderón-Zygmund operators, Proc. Amer. Math. Soc. Ser. B 1 (2014), 1-13.

[23] Z. SI AND Q. XUE, Weighted estimates for commutators of vector-valued maximal multilinear operators, Nonlinear Anal. 96 (2014) 96-108.

[24] Z. SI AND Q. XUE, Weighted estimates for vector-valued of commutators multilinear operators, Taiwanese J. Math. 17 (2013), 661-674.

[25] L. TANG, Weighted estimates for vector-valued commutators of multilinear operators, Proceedings of the Rayal Society of Edingburgh 138A (2008), 897-922.

[26] Q. XUE, Weighted estimates for the iterated commutators of multilinear maximal and fractonal type operators, Studia Math 217 (2013), 97-122. 